Anna Russo - Bertolt Brecht und Dario Fo 
Anna Russo

\section{Bertolt Brecht und Dario Fo}

Wege des epischen Theaters

Verlag J.B. Metzler

Stuttgart - Weimar 
Die Deutsche Bibliothek - CIP-Einheitsaufnahme

Russo, Anna :

Bertolt Brecht und Dario Fo : Wege des epischen Theaters / Anna Russo. Stuttgart ; Weimar : Metzler, 1998

ISBN 978-3-476-45206-1

ISBN 978-3-476-45206-1

ISBN 978-3-476-04300-9 (eBook)

DOI 10.1007/978-3-476-04300-9

Dieses Werk ist einschließlich aller seiner Teile geschützt. Jede Verwertung außerhalb der engen Grenzen des Urheberrechtsgesetzes ist ohne Zustimmung des Verlages unzulässig und strafbar. Das gilt insbesondere für die Vervielfältigungen, Übersetzung, Mikroverfilmungen und Einspeicherung in elektronischen Systemen.

M \& P Schriftenreihe für Wissenschaft und Forschung

(C) 1998 Springer-Verlag GmbH Deutschland

Ursprünglich erschienen bei J.B. Metzlersche Verlagsbuchhandlung und Carl Ernst Poeschel Verlag GmbH in Stuttgart 1998 
Diese Arbeit wurde unter dem Titel

Das Theater von Dario Fo der sechziger Jahre und seine Beziehungen zum epischen Theater Bertolt Brechts

als Dissertationsschrift angenommen.

Herrn Prof. Dr. Hans Vilmar Geppert und Herrn Dr. Hans Peter Plocher möchte ich für die Betreuung und die vielseitigen Anregungen in allen Phasen dieser Doktorarbeit danken.

Großen Dank schulde ich auch Herrn Hans Georg Hepermann für das sorgfältige Korrekturlesen. 


\section{INHALTSVERZEICHNIS}

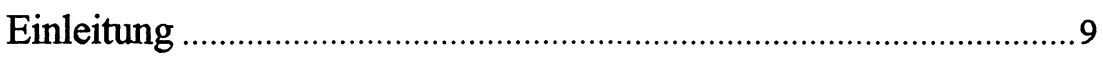

1. Es gibt eine Kultur des Volkes" ...................................14

1.1. "Das Volkstheater kann nur episch sein" ...........................19

2. Die Produktion innerhalb der bürgerlichen Säle .....25

2.1. Isabella, tre caravelle e un cacciaballe. Text und Aufführung .....................................................................30

2.1.1. Lieder oder Chöre als Praxis der Verfremdung...........................42

2.1.2. Parabel und Modell als Deutung der zeitgenössischen Realität ...57

2.1.2.1. Struktur und Lehrcharakter.......................................................57

2.1.2.2. Die Veränderung als Zielsetzung der Kritik.................................67

3. Die Produktion ausserhalb der bürgerlichen Säle ...71

3.1. Die Koexistenz zwischen Altem und Neuem. Die italienischen Bühnen von der Nachkriegszeit bis zum politischen Theater ....................................................71

3.2. Die Jahre der NUOVA SCENA …………………………..... 89

3.3. Mistero Buffo ………………………………………......98

3.3.1. Die Epik von Mistero Buffo. Methodische Prämisse ................ 118

3.3.1.1. Der Schauspieler in der Rolle des Erzählers ............................. 119

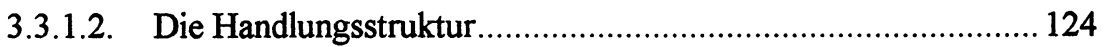

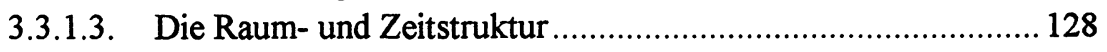

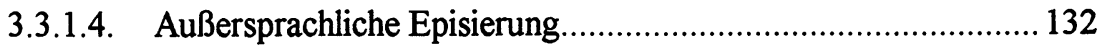

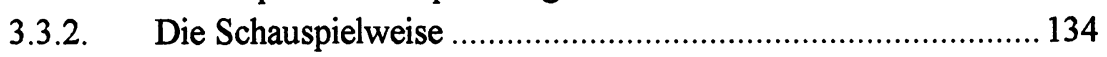

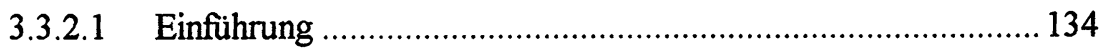

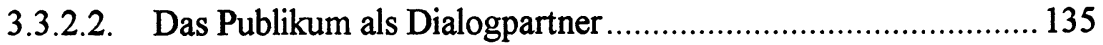

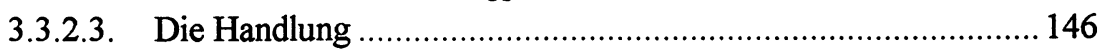


3.3.2.4. Analogien und Unterschiede zwischen Brecht und Fo im Bereich der Darstellung ........................................................ 156

4. Politisches Lehr- und Agitationstheater am Beispiel von Il Telaio

4.1. Die offene Dramaturgie im Dienst der Belehrung ....... 186

4.1.1. Das Publikum als Co-Produzent.......................................... 190

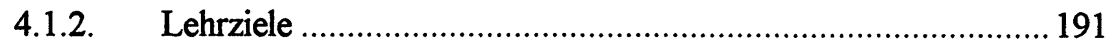

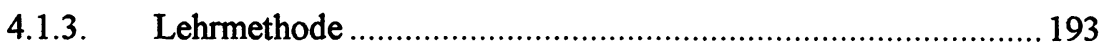

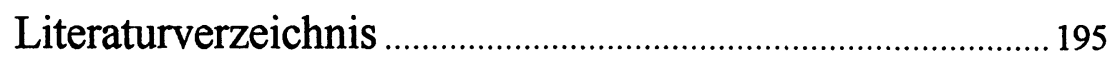

